\title{
Application of Taguchi approach to optimize friction stir welding parameters of polyethylene
}

\author{
M. A. REZGUI ${ }^{1,1}$, M. AYADI ${ }^{1}$, A. CHEROUAT ${ }^{2}$, K. HAMROUNI $^{3}$, A. ZGHAL $^{1}$, S. BEJAOUI $^{3}$ \\ ${ }^{1}$ UR-MSSDT, ESSTT, 5 Av Taha Hussein, Montfleury 1008 Tunis, TUNISIE \\ ${ }^{2}$ UTT- GAMMA INRIA, Domaine de Voluceau-Rocquencourt, 78153 Le Chesnay, France, \\ ${ }^{3}$ ISET Jendouba, Jendouba Nord Campus Universitaire 8019 TUNISIE
}

\begin{abstract}
This paper presents experimental and numerical results of butt friction stir welding of high density polyethylene. The FSW designed tool insulates the welded samples and preserves the heat gained from friction thus avoiding the appearance of blisters and splits after welding. The experimental tests, conducted according to combinations of process factors such as rotation speed, welding speed, pin diameter and hold time at beginning welding, were carried out according the Taguchi orthogonal table $\mathrm{L}_{27}$ in randomized way. Temperatures in the joint during the welding operation and flow stresses from the tensile tests of welded samples were measured and variances were analyzed. Identified models were used to simulate, by finite elements, the tensile tests performed on specimens having a weld cordon in their active area. The results show coherence between the numerical predictions and experimental observations in different cases of weld cordon mechanical behaviour.
\end{abstract}

Keywords: Friction Stir Welding, Polyethylene, ANOVA, Taguchi's Design, Experiment, Behaviour Model.

\section{Introduction}

The friction stir welding (FSW) is a relatively new welding process developed and patented by "Welding Institute" (TWI) in 1991. FSW is based on heat supplied by friction between the tool and the two parts to be welded and a strong plastic deformation in the material. The originality of this method is to weld components in solid state since the melting point of metallic materials is not reached during the process [1]. Therefore, the changes of phase are only in solid state, contrary to the traditional process of fusion welding which eliminates the shortcomings associated with the solidification and lead to lower internal stress compared to conventional welding.

Unlike metallic materials, polymers have a low hardness, a melting temperature very low reached quickly by the friction phenomenon, a very short time of solidification and a low thermal conductivity [2]. Therefore, rarely attempts were made to achieve a functional tool for FSW polymers [3]. A standard aluminium tool where pin and shoulder are connected, gave a bad roughness and a low tensile strength of welded joint. Under the effect of the inertia forces, parts of the polymeric particles rotated by the shoulder are ejected outside the mixed zone, causing a matter loss in the welded cordon. Another attempt, in which the tool consists of rotary pin, a thrust bearing

1 e-mail : Mohamedali.rezgui@gmail.com

This is an Open Access article distributed under the terms of the Creative Commons Attribution-Noncommercial License 3.0, which permits unrestricted use, distribution, and reproduction in any noncommercial medium, provided the original work is properly cited. 
and a not rotary shoulder, was successful. The rotating pin generates heat by friction in the joint and stirs the pasty matter thus carrying out a connection on an atomic scale. The shoulder slides along parts to be welded. It makes it possible to trap the molten matter and to apply a permanent pressure on the welded zone while material cools thus limiting the formation of air blisters. Furthermore, a heater mounted inside the shoulder provides heat power when the frictional heating is not sufficient [4]. Some polymers were subjected to FSW to evaluate the tensile strength of the weld and compare it to that of base material. The "Welding Institute" reported that they carried out the FSW of polypropylene, with a rate of maximum stress of welded joint of around $98 \%$ compared to the raw material.

In this study, thick sheets $(15 \mathrm{~mm})$ of very high density polyethylene (Code ISO 1043: HDPE) were chosen to be welded. It used in industry, Agro-industry, medical area and domestic.

\section{Materials and Methods}

The FSW of polymer is very sensitive to the rotation speed $\mathrm{N}$ and the welding speed $\mathrm{V}$ of the tool [5]. Three pins with different sizes were designed and manufactured as metric thread $(\mathrm{M} \phi)$. Pin diameter $\mathrm{M} \phi$ and friction surface $\mathrm{S}$ characterize approximately the cord width and stirred volume. The hold time Tm while the tool is pressed into the matter at the beginning of the welding operation, has also been considered as a factor. For these factors three levels are fixed (Table 1).

Table 1. Factors and levels of FSWP

\begin{tabular}{llccc}
\hline \multicolumn{1}{c}{ Facteurs } & Level 1 & Level 2 & Level 3 \\
\hline Pin rotation speed & $\mathrm{N}[\mathrm{tr} / \mathrm{min}]$ & 900 & 1280 & 1700 \\
Welding speed & $\mathrm{V}[\mathrm{mm} / \mathrm{min}]$ & 16 & 29 & 44 \\
Hold time & $\mathrm{Tm}[\mathrm{s}]$ & 9 & 15 & 20 \\
Pin size & $\mathrm{M} \phi[\mathrm{mm}]\left(\mathrm{S}\left[\mathrm{mm}^{2}\right]\right)$ & $\mathrm{M} 10(377)$ & $\mathrm{M} 12(452.5)$ & $\mathrm{M} 14(528)$ \\
\hline
\end{tabular}

The experimental weld operations were conducted according to the Taguchi orthogonal table $\mathrm{L}_{27}$ $\left(13^{3}\right)$ thus reducing time and number of experiences through reduction of experiment number from 81 to only 27. Indeed, factors and interactions are assigned in specific columns organized from predefined Taguchi linear graph (Figure 1) [6].

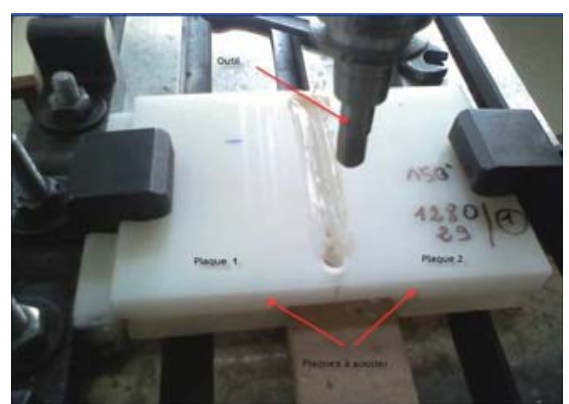

Fig. 1. Butt weld of HDPE thick sheet.
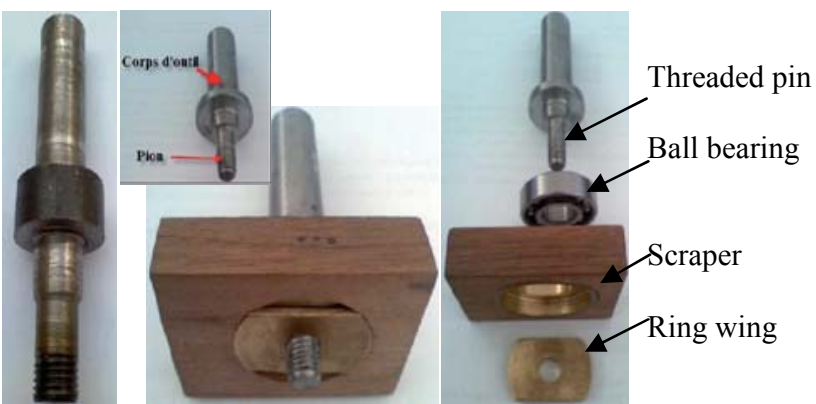

Fig. 2. Tool and scraper system

The 27 welding experiences were conducted on universal milling machine (Figure 1). Welding tools are made from steel bar (NE C48). They have a shoulder, a threaded pin having a height slightly less than the thickness of plates to weld and an upper part for their fixation on the rotary mandrel (Figure 2). Unlike previous studies [3] our preliminary welding tests showed that using a low thermal conductivity scraper retards the cooling of welded plates and contributes to a better distribution of temperature in the weld cordon. 
Table 2. Experimental data of polyethylene FSW (table $\mathrm{L}_{27}$ )

\begin{tabular}{c|cccc|cccr}
\hline \multicolumn{7}{c}{ Facteurs } & \multicolumn{4}{c}{ Réponses } \\
\hline Essai & $(1)$ & $(2)$ & $(5)$ & $(10)$ & & $\sigma_{2 \%}$ & $\sigma_{\text {flow }}$ & $\varepsilon_{\text {flow }}$ \\
$\mathrm{N}^{\circ}$ & $\mathrm{N}[\mathrm{rpm}]$ & $\mathrm{V}\left[\mathrm{mm} \mathrm{min}^{-1}\right]$ & $\mathrm{Tm}[\mathrm{s}]$ & $\mathrm{S}\left[\mathrm{mm}^{2}\right]$ & $\mathrm{T}\left[{ }^{\circ} \mathrm{C}\right]$ & {$[\mathrm{MPa}]$} & {$[\mathrm{MPa}]$} & {$[\%]$} \\
\hline 1 & 910 & 16 & 9 & 377 & 130 & 13,7 & 25,7 & 0,23 \\
2 & 910 & 16 & 15 & 452,5 & 145 & 11,5 & 24,2 & 0,23 \\
3 & 910 & 16 & 20 & 528 & 178 & 11,5 & 17,8 & 0,127 \\
4 & 910 & 29 & 9 & 452,5 & 145 & 8,8 & 28,7 & 0,274 \\
5 & 910 & 29 & 15 & 528 & 161 & 11,1 & 21,2 & 0,174 \\
6 & 910 & 29 & 20 & 377 & 135 & 11,3 & 23,4 & 0,179 \\
7 & 910 & 44 & 9 & 528 & 150 & 13,2 & 22,4 & 0,16 \\
8 & 910 & 44 & 15 & 377 & 128 & 10,2 & 23,5 & 0,21 \\
9 & 910 & 44 & 20 & 452,5 & 135 & 9,2 & 17,8 & 0,15 \\
10 & 1280 & 16 & 9 & 528 & 200 & 11,9 & 21,9 & 0,178 \\
11 & 1280 & 16 & 15 & 377 & 145 & 12,3 & 27,0 & 0,2 \\
12 & 1280 & 16 & 20 & 452,5 & 158 & 11,1 & 24,5 & 0,211 \\
13 & 1280 & 29 & 9 & 377 & 150 & 13,2 & 23,4 & 0,224 \\
14 & 1280 & 29 & 15 & 452,5 & 164 & 12,0 & 23,5 & 0,229 \\
15 & 1280 & 29 & 20 & 528 & 187 & 13,6 & 25,1 & 0,22 \\
16 & 1280 & 44 & 9 & 452,5 & 148 & 12,3 & 22,7 & 0,183 \\
17 & 1280 & 44 & 15 & 528 & 169 & 11,2 & 22,9 & 0,205 \\
18 & 1280 & 44 & 20 & 377 & 149 & 11,3 & 23,5 & 0,21 \\
19 & 1700 & 16 & 9 & 452,5 & 205 & 11,9 & 16,1 & 0,123 \\
20 & 1700 & 16 & 15 & 528 & 250 & 13,1 & 16,4 & 0,083 \\
21 & 1700 & 16 & 20 & 377 & 175 & 13,6 & 25,0 & 0,211 \\
22 & 1700 & 29 & 9 & 528 & 244 & 7,3 & 7,3 & 0,089 \\
23 & 1700 & 29 & 15 & 377 & 176 & 11,6 & 19,4 & 0,092 \\
24 & 1700 & 29 & 20 & 452,5 & 186 & 11,2 & 22,3 & 0,176 \\
25 & 1700 & 44 & 9 & 377 & 165 & 12,7 & 20,8 & 0,162 \\
26 & 1700 & 44 & 15 & 452,5 & 164 & 15,0 & 25,0 & 0,227 \\
27 & 1700 & 44 & 20 & 528 & 145 & 9,1 & 22,2 & 0,19 \\
\hline & & & & & & & & \\
\hline
\end{tabular}

The process dependent variables are the temperature $\mathrm{T}$ measured in the weld cordon during the welding operation and mechanical characteristics of the welded samples obtained from tensile tests. We considered the yield stress $\left(\sigma_{2 \%}\right)$ at $0.2 \%$ of strain and the first maximum stress $\left(\sigma_{\text {maxi }}\right.$ : flow stress) corresponding to strains lower than $50 \%$ (table 2). Furthermore, the tensile specimens have a standard geometry according to ISO3167 norm [7] and figure 3 shows the geometrical configuration of their cutting.

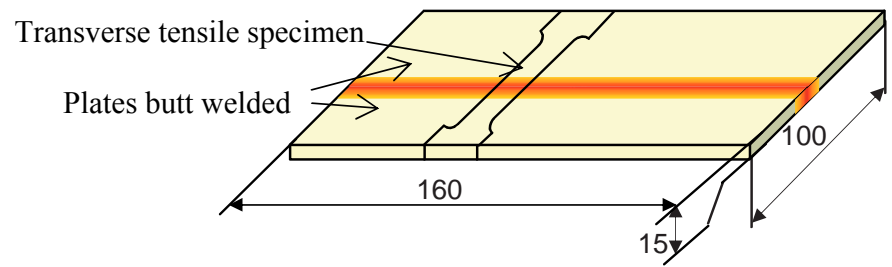

Fig. 3. Tensile specimen orientations

\section{Analyze of variance (ANOVA)}

The analyze of variance (ANOVA) method measures the effect of input variables (operating parameters of FSWP) on response variables (temperature and mechanical properties of welded 
joints) through the relationship between these two families of variables. The Fisher test is used to assess the degree of significance in these relationships. In this study, we analyzed the maximal temperature in the weld cordon during its formation and tensile yield stress of welded specimens.

\subsection{Temperature}

The ANOVA table 3 shows that only the angular speed $\mathrm{N}$, the welding speed $\mathrm{V}$ and the pin friction surface $\mathrm{S}$ have a statistically significant effect on maximum temperature at the $95,0 \%$ confidence level. This follows from the correlation between the mechanical power converted into heat, the operating parameters and geometrical tool involved in the FSWP.

Table 3. ANOVA of temperature T $(\alpha=5 \%, 1-\alpha=95 \%)$

\begin{tabular}{lrrrrc}
\hline $\begin{array}{c}\text { Source de } \\
\text { variation }\end{array}$ & dof & \multicolumn{1}{c}{ SS } & \multicolumn{1}{c}{ MS } & Fexp & Fthe(dof;6;5\%) \\
\hline N & 2 & 9132,52 & 4566,26 & $\mathbf{2 1 , 7 0}$ & 5,14 \\
V & 2 & 3472,52 & 1736,26 & $\mathbf{8 , 2 5}$ & 5,14 \\
Tm & 2 & 446,74 & 223,37 & 1,06 & 5,14 \\
S & 2 & 6434,30 & 3217,15 & $\mathbf{1 5 , 2 9}$ & 5,14 \\
\hline NxV & 4 & 1801,04 & 450,26 & 2,14 & 4,53 \\
NxTm & 4 & 1861,48 & 465,37 & 2,21 & 4,53 \\
VxTm & 4 & 228,81 & 57,20 & 0,27 & 4,53 \\
\hline Erreur & 6 & 1262,67 & 210,44 & & \\
\hline Total & 26 & 24640,07 & & \\
\hline
\end{tabular}

\subsection{Yield stress and maximum stress}

The ANOVA table 4 corresponding to the yield stress of welded samples shows that operating parameters and their interactions have not a statistically significant effect on maximum temperature at the $95.0 \%$ confidence level. Indeed, the mean of yield stresses of all welded samples is around of $11.7 \mathrm{MPa}$ in the same order that the base material, their absolute variation is about $1.5 \mathrm{MPa}$. This yield stress mean and its absolute variation can not be attributed to operating parameters. The flow stress results of welded joints showed at 5\% level significance the angular speed, pin frictional surface and interaction rotation speed welding speed have a significant effect on this constraint (Table 5).

Table 4. ANOVA of yield stress $\sigma e(\alpha=5 \%)$

Table 5. ANOVA of flow stress $\sigma \max (\alpha=5 \%)$

\begin{tabular}{|c|c|c|c|c|c|c|c|c|c|c|c|}
\hline $\begin{array}{l}\text { Source of } \\
\text { variation }\end{array}$ & dof & SS & MS & Fexp & $\begin{array}{c}\text { Fthe } \\
\text { (dof;6;5\%) }\end{array}$ & $\begin{array}{l}\text { Source of } \\
\text { variation }\end{array}$ & dof & SS & MS & Fexp & $\begin{array}{c}\text { Fthe } \\
\text { (dof; } 6 ; 5 \%)\end{array}$ \\
\hline $\mathrm{N}$ & 2 & 4,08 & 2,04 & 1,17 & 5,14 & $\mathrm{~N}$ & 2 & 95,08 & 47,54 & 15,32 & 5,14 \\
\hline V & 2 & 6,20 & 3,10 & 1,78 & 5,14 & V & 2 & 2,49 & 1,25 & 0,40 & 5,14 \\
\hline $\mathrm{Tm}$ & 2 & 2,08 & 1,04 & 0,60 & 5,14 & $\mathrm{Tm}$ & 2 & 13,66 & 6,83 & 2,20 & 5,14 \\
\hline $\mathrm{S}$ & 2 & 4,11 & 2,06 & 1,18 & 5,14 & $\mathrm{~S}$ & 2 & 72,18 & 36,09 & 11,63 & 5,14 \\
\hline $\mathrm{NxV}$ & 4 & 15,71 & 3,93 & 2,26 & 4,53 & $\mathrm{NxV}$ & 4 & 78,80 & 19,70 & 6,35 & 4,53 \\
\hline NxTm & 4 & 12,08 & 3,02 & 1,74 & 4,53 & NxTm & 4 & 157,54 & 39,39 & 12,69 & 4,53 \\
\hline VxTm & 4 & 20,59 & 5,15 & 2,96 & 4,53 & VxTm & 4 & 21,35 & 5,34 & 1,72 & 4,53 \\
\hline Erreur & 6 & 10,42 & 1,74 & & & Erreur & 6 & 18,62 & 3,10 & & \\
\hline Total & 26 & 75,27 & & & & Total & 26 & 459,74 & & & \\
\hline
\end{tabular}




\section{Behaviour modelling}

\subsection{Macroscopic Observations}

Tensile tests carried out on welded specimens having a cordon on their central active area, showed three types of failures (Figure 4). Failures caused by great strain located in the base material. Failures resulting from large strain located in the weld cordon and failures produced without significant deformation occurring at the weld cordon center.

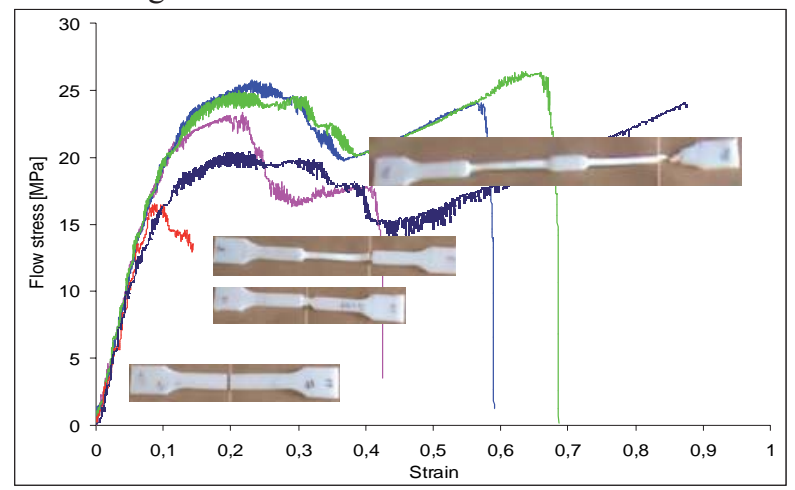

Fig. 4. Differents types of failures

These observations show that failures, observed in the areas where large strain occurred, are the indicators of the local mechanical properties inhomogeneity of the tensile welded specimen. However, failures without appreciable strain in weld cordon result from a matter discontinuity. This defect could be detected by observation under the optical microscope (Figure 5), for the junctions made at temperatures above $180^{\circ} \mathrm{C}$. The discontinuity can be caused by combined effects of overheating and the superficial tension of matter in liquid phase.

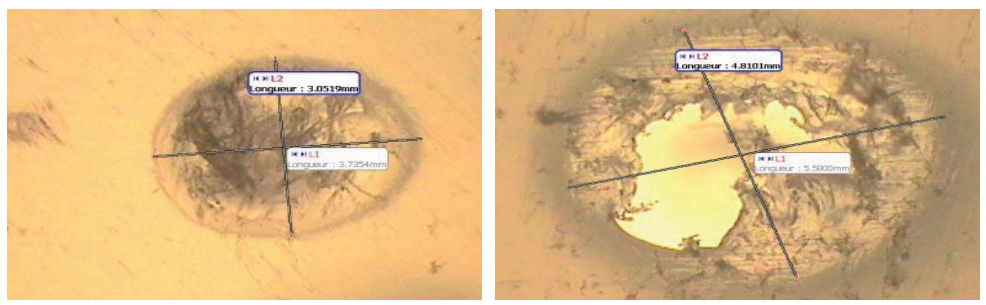

Fig. 5. Air blisters defaults

\subsection{Stress/strain relationship}

The rational tensile curves (Figure 6) make it possible to distinguish, from the stresses according to the inelastic strain, two evolution stages. The first corresponds to strain ranging between 5 and $55 \%$. The second is linear; corresponding to strain above $60 \%$ and exceeds $150 \%$ for other tests. The experimental observations made it possible to adjust the stress-strain relationship for an isothermal tensile test by the following model:

$$
\sigma=K_{1}\left(\varepsilon_{0}+\varepsilon_{i}\right)^{n_{1}} \exp \left(-\alpha \varepsilon_{i}^{n_{2}}\right)+K_{2} \varepsilon_{i}
$$

Where $\sigma$ is rational stress, $\varepsilon_{i}$ inelastic strain and $K_{l}, K_{2}, \varepsilon_{0}, n_{l}, n_{2}, \alpha$ are the model coefficients. The determination of the model coefficients is made, as illustrated in figure 6 , by calibrating the model on the experimental curves, the calibration results are presented in Table 7. 

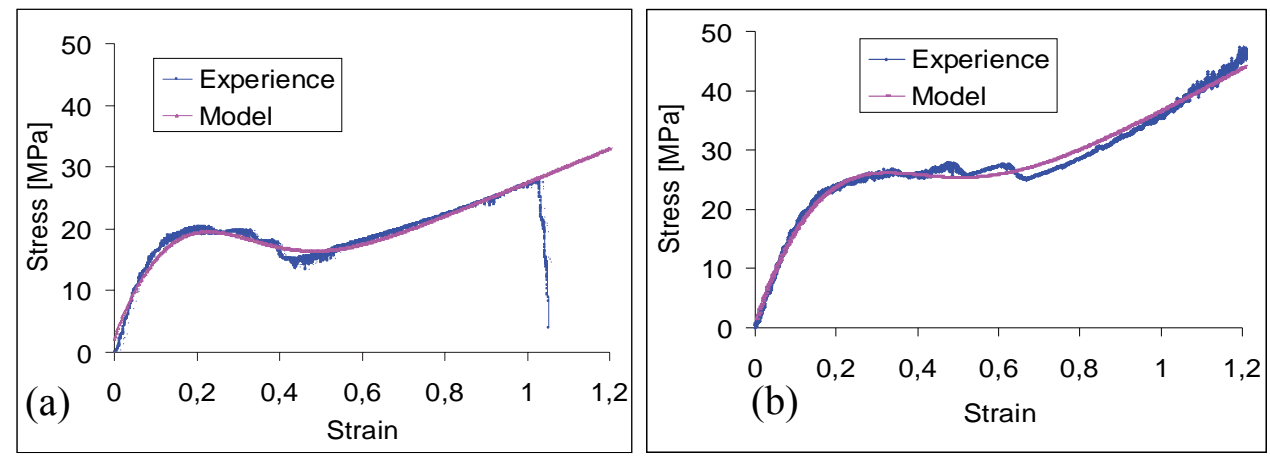

Fig. 6. Rational curves of tensile tests

(a) Tensile specimen made of base material - (b) Tensile specimen with butt Weld cordon

Table 7. Model coefficients

\begin{tabular}{|c|c|c|c|c|c|c|}
\hline & $\mathrm{K}_{1}[\mathrm{MPa}]$ & $\mathrm{K}_{2}[\mathrm{MPa}]$ & $\varepsilon_{0}$ & $\mathrm{n}_{1}$ & $\mathrm{n}_{2}$ & $\alpha$ \\
\hline Base material & 70.3 & 27.4 & 0.008 & 0.73 & 1.92 & 10.5 \\
\hline Butt weld Cordon & 94.0 & 36.6 & 0.006 & 0.82 & 1.68 & 7.5 \\
\hline
\end{tabular}

\section{3 tensile tests simulation}

The identified models were used to simulate, by ABAQUS finite element code, the experimental tensile tests performed on tensile specimens having a weld cordon width of $14 \mathrm{~mm}$ situated in the central zone of the active area. The analysis results (Figure 7) shows a coherence between the numerical predictions and experimental observations when the mechanical properties of the base material are much lower than those of the weld cordon. The most important strain concerns the only base material. It seems they are governed by the flow stress recorded in the strains zone lower than $45 \%$.

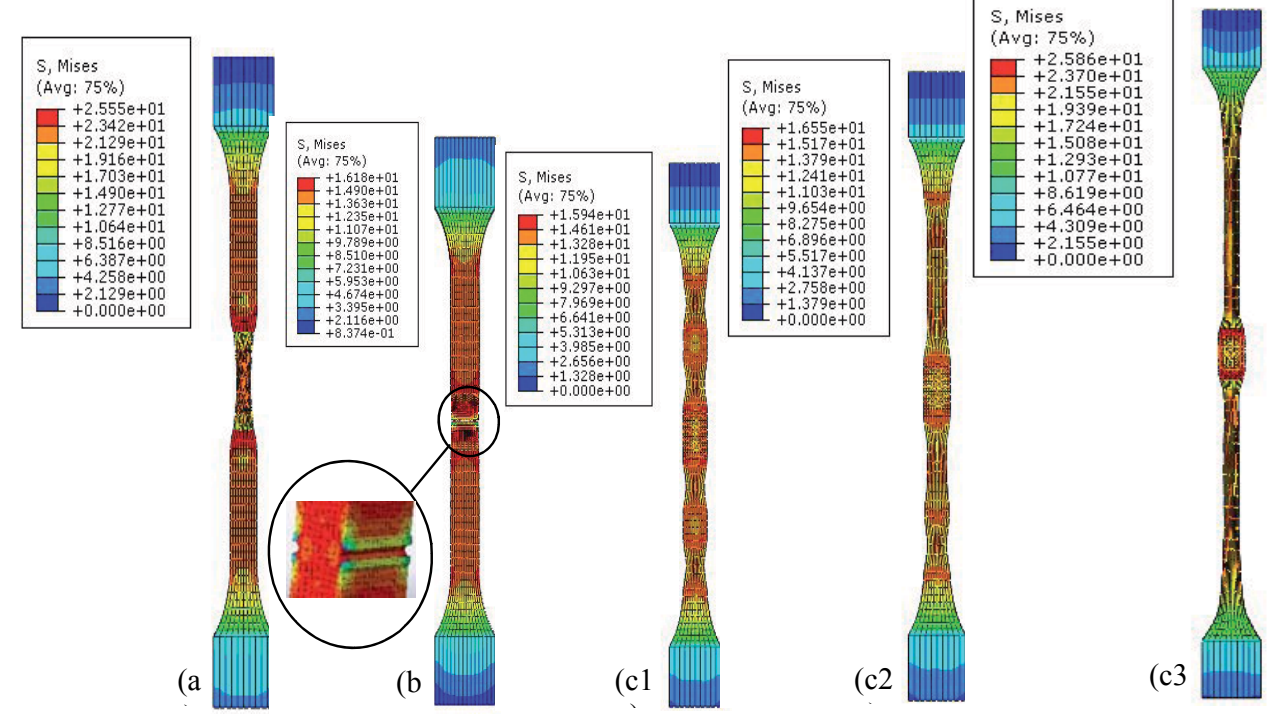

Fig. 7. Numerical predictions and localization of large strain of welded samples.

(a) Mild cordon - (b) Discontinuity in weld cordon

(c) Strengthen cordon for various imposed displacement: (c1) $32 \mathrm{~mm}-$ (c2) $43 \mathrm{~mm}-$ (c3) $98 \mathrm{~mm}$ 
For other tests, experience has shown that the presence of the weld cordon was either the cause of localization of highest inelastic strain either the cause of premature rupture without strain. The numerical simulations prove that the first case corresponds to a weld cordon having mechanical properties inferior to those of the base material (Figure 6a). The second case can be attributed to the discontinuity in the weld cordon. The behaviour inhomogeneities can appear either as a strengthened cordon or a mild cordon, else in local defects form.

\section{Discussions}

The thermal measurements recorded during different welding show that in the range of rotation speed 900-1700 rpm and of welding speed 16 and $44 \mathrm{~mm} \cdot \mathrm{min}^{-1}$, the reached temperature levels vary between 120 and $180^{\circ} \mathrm{C}$. This proves that the welding of HDPE is produced in a liquid state by melting the material. Indeed, the HDPE's thermal properties are favourable to reduction in the heat affected zone size. In addition, a scraper used to limit energy loss outward weld plates, seems to improve significantly both aesthetic aspect and mechanical property of the welded parts. The comparison between experimental observations and numerical predictions for the tensile tests of welded samples indicates that mechanical properties of weld cordon are dependent on welding parameters. For safe welded parts, two behaviours were observed. The first corresponds to the presence of a weld cordon more deformable than the base material; the second corresponds to the presence of a weld cordon less deformable than the base material (Figure 7). This finding lets admitting to the existence of an intermediate configuration of operational parameters for obtaining weld joint with mechanical properties very close to the base material.

\section{Conclusion and perspective}

The study highlighted the promises and difficulties of FSW of HDPE. The large number of parameters affecting the mechanical properties of welded joints requires planning characterization tests; this reduces time and cost of experiments. The obtained results showed the feasibility of welding operations as well as good mechanical properties of HDPE's mechanical assemblies; they could be comparable to the base material. Moreover, the thermal measurements have proved that the welding takes place in liquid phase after melting of the material. More precautions should be taken as regards of FSW tools avoiding losses energy and material. The characterization tests at controlled temperatures are likely to provide more accuracy in behaviour models building. This is a future subject of investigation where the modelling, identification and numerical simulation take all their dimensions to predict the polymer welded structures behaviour.

\section{References}

1. R.S. Mishra, Z.Y. Ma, Friction Stir welding and processing, Journal of Materials Science and Engineering R 50, 1-78 (2005).

2. K. Labastie Coeyrehourcq, Etude méthodes rapides d'analyse de la structure moléculaire du polyéthylène, $\mathrm{PhD}$ Thesis, Ecole des Mines de Paris, Spécialité "Science et Génie des Matériaux", (2003)

3. T. Nelson, Friction Stir Welding of Polymeric Materials, World Intellectual Property Organisation, WO 01/85383-A1, (2001).

4. Seth R. Strand, Effects of Friction Stir Welding on "Polymer Microstructure, MSc Thesis, Brigham Young University, (2004).

5. Z. Kiss, T. Czigány, Applicability of friction stir welding polymeric materials, Periodica polytechnica Mechanical Engineering 51/1 15-18 (2007)

6. G. Baillargeon, Expérimentation en Milieu Industriel: Méthodes Taguchi, Les Editions SMG, ISBN 2-89094-057-8, Trois-Rivières Qc (1993). 
7. J. P. Trotignon, J. Verdu, A. Dobraczynski, M. Piperaud, Précis Matières plastiques, AFNOR/Nathan (1996).

8. A. Scialpi, M. Troughton, S. Andrews, L.A.C.De Filippis, In-line reciprocating friction stir welding of plastics, Published in Joining Plastics/Fügen von Kunststoffen Magazine, Issue 1, (2007). 